УДК 633.11»324»:631.55:631.92

https://doi.org/10.32634/0869-8155-2020-342-10-60-63

Тип статьи: Оригинальное исследование

Type of article: Original research

Хрипунов А.И.,

Общия E.H.

Галушко Н.А.

ФГБНУ Северо-Кавказский Федеральный научный аграрный центр Ставропольский край, Россия

E-mail: sniish@mail.ru, obzia@mail.ru,

sniish@mail.ru,anna.v.nazarova@mail.ru

Ключевые слова: озимая пшеница, структура урожая, предшественники, фон питания, ландшафтные условия

Для цитирования: Хрипунов А.И., Общия Е.Н., Галушко Н.А. Формирование элементов структуры урожая озимой пшеницы в ландшафтных условиях Центрального Предкавказья. Аграрная наука. 2020 342 (10): 60-63.

https://doi.org/10.32634/0869-8155-2020-342-10-60-63

Конфликт интересов отсутствует

Alexander I. Khripunov,

Elena N. Obshchiya,

atalia A. Galushko

North Caucasus Federal Agrarian Research Centre

sniish@mail.ru,

obzia@mail.ru, sniish@mail.ru

Key words: winter wheat, crop structure, predecessors, nutrition background, landscape conditions

For citation: Khripunov A.I., Obshchiya E.N., Galushko N.A. Formation of structure elements of winter wheat yield in landscape conditions of the Central Ciscaucasia. Agrarian Science. 2020; 342 (10): 60-63. (In Russ.)

https://doi.org/10.32634/0869-8155-2020-342-10-60-63

There is no conflict of interests
Формирование элементов структуры урожая озимой пшеницы в ландшафтных условиях Центрального Предкавказья

\begin{abstract}
PEЗЮME
Актуальность. Уровень урожайности существенно зависит от агротехники возделывания и ландшафтных условий. Поэтому знание механизма взаимоотношения между этими факторами и растением актуально.

Методика. Опыт проводили в 2015-2019 годах на полигоне «Агроландшафт». Цель исследований - изучить влияние предшественников, уровня минерального питания и местоположения в рельефе на формирование элементов структуры урожая озимой пшеницы в зоне неустойчивого увлажнения Ставропольского края.

Результаты. Урожайность по гороху формировалась в 2015 году по типу высоких стеблестоев, в 2017 году - по смешанному типу, в остальные годы - по колосовому типу. На таксоне $\mathrm{A}_{1}$ урожай зависел от массы зерна с колоса в сильной $(r=0,85)$, а на $\mathrm{A}_{3}-$ в средней степени $(r=0,60)$. По полупару формирование шло в 2015 году за счет продуктивного стеблестоя $(r=0,78)$ и массы зерна с колоса $(r=0,71)$, в 2016-2019 годах по колосовому типу $(r=0,76-0,96)$. На таксоне $\mathrm{A}_{1}$ урожай формировался за счет массы зерна с колоса $(r=0,83)$, а на таксоне $\mathrm{A}_{2}$ и $\mathrm{A}_{3}-$ за счет стеблестоя $(r=0,84-0,85)$. По гороху достоверная разница между фонами питания была по всем элементам структуры урожая, кроме массы зерна с колоса, а по полупару - только по количеству продуктивных стеблей. В среднем по предшественникам достоверная разница по таксонам отмечена между $\mathrm{A}_{1}$ и $\mathrm{A}_{2}$ по количеству зерен и массе зерна с колоса, между $\mathrm{A}_{2}$ и $\mathrm{A}_{3}$ - по стеблестою, между $\mathrm{A}_{1}$ и $\mathrm{A}_{3}$ - по всем элементам структуры урожая. Наиболее сильная связь урожайности отмечалась с массой зерна с колоса $(r=0,88)$, который тесно связан с массой 1000 зерен $(r=0,83)$ и количеством зерен в колосе $(r=0,82)$.
\end{abstract}

\section{Formation of structure elements of winter wheat yield in landscape conditions of the Central Ciscaucasia}

\begin{abstract}
Relevance. The yield level significantly depends on the cultivation technique and landscape conditions. Therefore, knowledge of the mechanism of the relationship between these factors and the plant is relevant.

Methods. The experiment was carried out in 2015-2019 at the "Agro landscape" training ground. The aim of the research was to study the influence of predecessors, the level of mineral nutrition and location in the relief on the formation of elements of the structure of the yield of winter wheat in the zone of unstable moisture in the Stavropol Territory.

Results. The pea yield was formed in 2015 by the type of tall stalks, in 2017 by the mixed type, in other years by the spike type. On taxon $A_{1}$, the yield depended on the grain weight per year in a strong $(r=0.85)$, and on $\mathrm{A}_{3}$, in an average $(r=0.60)$. For the halffallow, the formation proceeded in 2015 due to the productive stalk $(r=0.78)$ and grain weight per ear $(r=0.71)$, in 2016-2019. according to the spike type $(r=0.76-0.96)$. In taxon $\mathrm{A}_{1}$, the yield was formed due to the weight of grain per ear $(r=0.83)$, and in taxon $A_{2}$ and $A_{3}$, due to the stem $(r=0.84-0.85)$. For peas, a significant difference between the nutritional backgrounds was for all elements of the crop structure, except for the weight of grain per ear, and for half-fallow only in the number of productive stems. On average for predecessors, a significant difference in taxa was noted between $A 1$ and $A_{2}$ in the number of grains and grain weight per ear, between $A_{2}$ and $A_{3}$ in the stem, between $A_{1}$ and $A_{3}$ in all elements of the crop structure. The strongest relationship between yield was noted with the weight of grain per ear $(r=0.88)$, which is closely related to the weight of 1000 grains $(r=0.83)$ and the number of grains per ear $(r=0.82)$.
\end{abstract}




\section{Введение}

На формирование урожая и основных элементов его структуры значительное влияние оказывают природно-климатические условия зоны возделывания, уровень агротехники, особенности сорта, внесение удобрений, ландшафтные условия [1-3].

Основные элементы структуры урожая озимой пшеницы: густота стояния растений, продуктивная кустистость, число зерен на один колос и масса 1000 зерен формируются в определенные этапы органогенеза [4].

Вклад отдельных элементов структуры в повышение урожайности по регионам значительно различается, что используется в селекционном процессе в качестве маркера. Учет целенаправленного влияния различных факторов на формирование урожая и определенных элементов его структуры позволяет совершенствовать агротехнику возделывания [5,6].

Цель исследований - изучить влияние предшественников, уровня минерального питания и местоположения в рельефе на формирование элементов структуры урожая и урожайность озимой пшеницы в зоне неустойчивого увлажнения Ставропольского края.

Условия, материалы и методы исследования

Исследования проводили в 2015-2019 годах на экспериментальном полигоне ФГБНУ Северо-Кавказского Федерального научного аграрного центра «Агроландшафт», относящегося к урочищу Балки Ташлянского ландшафта байрачных лесостепей и расположенного в верховьях бассейна реки Кизиловки. Полигон создан в 1996 году на склоновых землях от 2о до 5о на площади 216 га и представлен в виде действующей модели фермерского хозяйства. Землепользование организовано на ландшафтных принципах, подразумевающих оценку таксонометрических единиц ранга урочищ, подурочищ и фаций для эффективного сельскохозяйственного использования. Ландшафтное картирование выявило: $A_{1}$ - подурочище окраины плакора; $A_{2}$ - подурочище верхней части склона, $A_{3}$ - подурочище нижней части склона. Дифференцирующими показателями выделения подурочищ на плакоре являются запасы гумуса и мощность почв, а на склоне - почвообразующие породы. Равномерно рассредоточенные по территории участки залужения сеть лесных, кустарниковых и агростепных полос, резерваты, дороги создают линейный каркас противоэрозионной устойчивости, частота размещения которого определяется рельефом, геологическими и почвенными условиями землепользования.

Характеристика почвенного покрова и рельефа участка:

таксон $\mathrm{A}_{3}$ содержит 3,7\% гумуса, $\mathrm{P}_{2} \mathrm{O}_{5}-10 \mathrm{Mг} / \mathrm{K} \Gamma, \mathrm{K}_{2} \mathrm{O}-223 \mathrm{Mг} / \mathrm{Kг}$, мощность профиля - $71 \mathrm{~cm}$, балл бонитета - 48, характер рельефа склон коренной;

таксон $\mathrm{A}_{2}$ содержит 3,2\% гумуса, $\mathrm{P}_{2} \mathrm{O}_{5}-21 \mathrm{Mr} / \mathrm{Kr}, \mathrm{K}_{2} \mathrm{O}-205 \mathrm{Mr} / \mathrm{Kг}$, мощность профиля - 81 см, балл бонитета - 45, характер рельефа - склон коренной;

таксон $\mathrm{A}_{1}$ содержит 2,3\% гумуса, $\mathrm{P}_{2} \mathrm{O}_{5}-10 \mathrm{Mг} / \mathrm{Кг}$, $\mathrm{K}_{2} \mathrm{O}-133 \mathrm{мг/Кг,} \mathrm{мощность} \mathrm{профиля}-59 \mathrm{~cm}$, балл бонитета - 37, характер рельефа - плакор.

Районированный сорт озимой пшеницы Багира селекции нашего центра размещали после гороха на зерно и озимой пшеницы на двух фонах питания: неудобренном (контроль) и удобренном фоне. Минеральные удобрения в виде нитроаммофоски применялись под предпосевную культивацию в дозе $\mathrm{N}_{40} \mathrm{P}_{40} \mathrm{~K}_{40}$. В опыте применялась рекомендованная для зоны неустойчивого увлажнения агротехника возделывания полевых культур. Общая площадь делянки $-72 \mathrm{~m}^{2}$, учетная $-18 \mathrm{~m}^{2}$. Повторность опыта - трехкратная. Опыт заложен по 3-факториальной схеме: $\mathrm{A}_{2} \mathrm{~B}_{2} \mathrm{C}_{3}$.

Фактор A - фон питания:

1 - контроль;

$2-\mathrm{N}_{40} \mathrm{P}_{40} \mathrm{~K}_{40}$

Фактор В - предшественники:

1 - горох;

2 - озимая пшеница.

Фактор C - местоположение в рельефе:

1 - почвы плакора, чернозем обыкновенный, слабогумусированный, щебенчато-супесчаный (легкий суглинок), крутизна $1,3^{\circ}$;

2 - почва коренных склонов, $3^{\circ}$ Ю-В экспозиции, чернозем обыкновенный, слабогумусированный, супесчаный, легкосуглинистый;

3 - почва склонов речных долин, 3,4ํ-ЮВ экспозиции, чернозем обыкновенный, среднемощный, среднесуглинистый.

Таблица 1. Влияние условий минерального питания на формирование элементов структуры урожая озимой пшеницы по предшественнику горох, среднее по таксонам

Table 1. Influence of the conditions of mineral nutrition on the formation of elements of the structure of the yield of winter wheat for the predecessor peas, average for taxa

\begin{tabular}{|c|c|c|c|c|c|c|}
\hline Годы & $\begin{array}{c}\text { Фон пита- } \\
\text { ния }\end{array}$ & $\begin{array}{c}\text { Количество } \\
\text { продуктивных } \\
\text { стеблей к уборке, } \\
\text { шт./м² }\end{array}$ & $\begin{array}{c}\text { Число } \\
\text { зерен в } \\
\text { колосе, шт. }\end{array}$ & $\begin{array}{c}\text { Масса } \\
1000 \\
\text { зерен, г }\end{array}$ & $\begin{array}{c}\text { Масса зерна } \\
\text { с колоса, г }\end{array}$ & $\begin{array}{c}\text { Урожайность } \\
\text { зерна, т/га }\end{array}$ \\
\hline \multirow{2}{*}{2015} & Контроль & 399,3 & 25,4 & 36,2 & 0,92 & 3,65 \\
\hline & $\mathrm{N}_{40} \mathrm{P}_{40} \mathrm{~K}_{40}$ & 463,0 & 26,1 & 38,1 & 0,99 & 4,60 \\
\hline & $p$ & 0,036 & 0,083 & 0,064 & 0,092 & 0,041 \\
\hline \multirow{2}{*}{2016} & Контроль & 384,3 & 15,2 & 41,7 & 0,64 & 2,45 \\
\hline & $\mathrm{N}_{40} \mathrm{P}_{40} \mathrm{~K}_{40}$ & 416,0 & 17,2 & 45,3 & 0,78 & 3,23 \\
\hline & $p$ & 0,052 & 0,046 & 0,040 & 0,038 & 0,044 \\
\hline \multirow{2}{*}{2017} & Контроль & 366,0 & 30,8 & 43,0 & 1,31 & 4,78 \\
\hline & $\mathrm{N}_{40} \mathrm{P}_{40} \mathrm{~K}_{40}$ & 493,7 & 26,7 & 44,0 & 1,18 & 5,83 \\
\hline & $p$ & 0,032 & 0,035 & 0,062 & 0,081 & 0,045 \\
\hline \multirow{2}{*}{2018} & Контроль & 231,3 & 29,2 & 36,0 & 1,08 & 2,57 \\
\hline & $\mathrm{N}_{40} \mathrm{P}_{40} \mathrm{~K}_{40}$ & 372,0 & 25,2 & 38,3 & 1,00 & 3,63 \\
\hline & $p$ & 0,029 & 0,031 & 0,046 & 0,118 & 0,042 \\
\hline \multirow{2}{*}{2019} & Контроль & 453,3 & 29,7 & 35,1 & 1,05 & 4,75 \\
\hline & $\mathrm{N}_{40} \mathrm{P}_{40} \mathrm{~K}_{40}$ & 513,7 & 27,8 & 37,0 & 0,99 & 5,16 \\
\hline & $p$ & 0,052 & 0,045 & 0,042 & 0,087 & 0,058 \\
\hline \multirow{2}{*}{$\begin{array}{l}\text { сред- } \\
\text { нее }\end{array}$} & Контроль & 366,8 & 26,1 & 38,4 & 1,00 & 3,64 \\
\hline & $\mathrm{N}_{40} \mathrm{P}_{40} \mathrm{~K}_{40}$ & 451,7 & 24,6 & 40,5 & 0,99 & 4,49 \\
\hline & $p$ & 0,028 & 0,046 & 0,044 & 0,095 & 0,041 \\
\hline
\end{tabular}


Летне-осенний период 2014, 2015, 2017 и 2018 гг. был очень засушливым: ГТК с июля по октябрь составил соответственно 0,53; 0,30; 0,49 и 0,85. В весенне-летний период 2015 г. апрель был очень засушливым (ГТК=0,09), а июнь засушливым (ГТК=0,74). В 2016 г. апрель был жарким и засушливым (ГТК=0,48), а май и июнь - избыточно увлажненными (ГТК, соответственно, 2,19 и 1,40). Май и июнь 2017 г. в целом были влажными и теплыми (ГТК соответственно 3,9 и 1,44). В апреле и июне 2019 г. наблюдалась сильная двухмесячная засуха (ГТК 0,02 и 0,39).

Таким образом, в большинстве лет осенние месяцы характеризовались пониженным температурным режимом и значительным недобором осадков. Зима была короткой и относительно теплой, а весна - ранней. В среднем за 5 лет самым засушливым был апрель (ГТК = 0,3), засушливым - июнь (ГТК $=0,81)$, а избыточно влажным - май $(Г T К=1,92)$.

Уборку озимой пшеницы проводили прямым комбайнированием САМПО - 130 в фазу полной спелости зерна. Урожайность пересчитывали на $14 \%$ влажность. Статистическая обработка данных осуществляли по Б.А. Доспехову [7], используя программу AgCStat для Excel и пакет прикладных программ SPSS V24.0.

\section{Результаты исследований}

В среднем по таксонам по предшественнику горох установлена достоверная математическая разница между фонами питания по числу зерен в колосе и урожайностью по 4 годам (соответственно 2016-2019 и 2015-2018), по количеству продуктивных стеблей к уборке и массе 1000 зерен по 3 годам $(2015,2017$, 2018 и 2016, 2018, 2019) и по выходу зерна с 1 колоса - по 1 году (табл. 1).

Урожайность озимой пшеницы по предшественнику горох формировалась в разные годы по-разному. Так, в 2015 г. урожай зерна формировался по типу высоких стеблестоев, т.е. за счет продуктивного количества стеблей к уборке $(r=0,94)$. В 2017 г. этот процесс шел по смешанному типу за счет стеблестоя $(r=0,62)$ и массы зерна с колоса $(r=0,59)$, а в 2016, 2018 и 2019 гг. - по колосовому типу за счет массы зерна с колоса (соответственно $r=0,96 ; 0,81$ и 0,94). Максимально тесная корреляционная связь между урожайностью и количеством зерен в колосе
Таблица 2. Влияние условий минерального питания на формирование элементов структуры урожая озимой пшеницы по полупару, среднее по таксонам

Table 2. Influence of conditions of mineral nutrition on the formation of elements of the structure of the yield of winter wheat by semi-fallow, average for taxa

\begin{tabular}{|c|c|c|c|c|c|c|}
\hline Годы & Фон питания & $\begin{array}{c}\text { Количество } \\
\text { продуктивных } \\
\text { стеблей к уборке, } \\
\text { шт./м² }\end{array}$ & $\begin{array}{c}\text { Число зерен } \\
\text { в колосе, } \\
\text { шт. }\end{array}$ & $\begin{array}{c}\text { Масcа } \\
1000 \\
\text { зерен, г }\end{array}$ & $\begin{array}{l}\text { Масса зерна } \\
\text { с } 1 \text { колоса, г }\end{array}$ & $\begin{array}{c}\text { Урожай } \\
\text { зерна, т/га }\end{array}$ \\
\hline \multirow{3}{*}{2015} & Контроль & 333,0 & 25,9 & 38,5 & 0,99 & 3,28 \\
\hline & $\mathrm{N}_{40} \mathrm{P}_{40} \mathrm{~K}_{40}$ & 405,0 & 25,5 & 41,2 & 1,05 & 4,27 \\
\hline & $p$ & 0,052 & 0,124 & 0,046 & 0,072 & 0,040 \\
\hline \multirow{2}{*}{2016} & Контроль & 267,0 & 16,0 & 40,0 & 0,66 & 1,76 \\
\hline & $\mathrm{N}_{40} \mathrm{P}_{40} \mathrm{~K}_{40}$ & 390,0 & 16,3 & 43,4 & 0,72 & 2,81 \\
\hline \multirow{3}{*}{2017} & $p$ & 0,023 & 0,136 & 0,040 & 0,065 & 0,038 \\
\hline & Контроль & 314,7 & 25,4 & 40,5 & 1,03 & 3,24 \\
\hline & $\mathrm{N}_{40} \mathrm{P}_{40} \mathrm{~K}_{40}$ & 426,7 & 25,7 & 39,6 & 1,01 & 4,31 \\
\hline & $p$ & 0,039 & 0,138 & 0,067 & 0,118 & 0,036 \\
\hline \multirow{2}{*}{2018} & Контроль & 283,7 & 23,4 & 41,5 & 0,99 & 2,85 \\
\hline & $\mathrm{N}_{40} \mathrm{P}_{40} \mathrm{~K}_{40}$ & 429,0 & 22,6 & 39,9 & 0,93 & 3,86 \\
\hline \multirow{3}{*}{2019} & $p$ & 0,001 & 0,082 & 0,064 & 0,093 & 0,040 \\
\hline & Контроль & 408,3 & 23,8 & 37,3 & 0,91 & 3,70 \\
\hline & $\mathrm{N}_{40} \mathrm{P}_{40} \mathrm{~K}_{40}$ & 424,0 & 30,3 & 34,4 & 1,03 & 4,38 \\
\hline \multirow{3}{*}{$\begin{array}{l}\text { сред- } \\
\text { нее }\end{array}$} & $\mathrm{p}$ & 0,086 & 0,041 & 0,042 & 0,081 & 0,055 \\
\hline & Контроль & 321,3 & 22,9 & 39,6 & 0,92 & 2,97 \\
\hline & $\mathrm{N}_{40} \mathrm{P}_{40} \mathrm{~K}_{40}$ & 414,9 & 24,1 & 39,7 & 0,95 & 3,93 \\
\hline & $p$ & 0,044 & 0,076 & 0,126 & 0,084 & 0,042 \\
\hline
\end{tabular}

Таблица 3. Урожайность и элементы структуры урожая озимой пшеницы по таксонам и годам исследований на удобренном фоне, среднее по предшественникам

Table 3. Yield and elements of the structure of winter wheat yield by taxa and years of research on a fertilized background, average for predecessors

\begin{tabular}{|c|c|c|c|c|c|c|}
\hline Таксон & Годы & $\begin{array}{c}\text { Количество продук- } \\
\text { тивных стеблей к } \\
\text { уборке, шт./м² }\end{array}$ & $\begin{array}{l}\text { Число зерен в } \\
\text { колосе, шт. }\end{array}$ & $\begin{array}{c}\text { Macca } \\
1000 \\
\text { зерен, г }\end{array}$ & $\begin{array}{c}\text { Масса } \\
\text { зерна с } 1 \\
\text { колоса, г }\end{array}$ & $\begin{array}{c}\text { Урожай } \\
\text { зерна, } \\
\text { т/га }\end{array}$ \\
\hline \multirow{6}{*}{$A_{1}$} & 2015 & 383 & 23,2 & 40,4 & 0,94 & 3,58 \\
\hline & 2016 & 410 & 11,3 & 41,1 & 0,46 & 1,89 \\
\hline & 2017 & 448 & 19,6 & 42,1 & 0,83 & 3,73 \\
\hline & 2018 & 438 & 16,2 & 27,9 & 0,45 & 1,98 \\
\hline & 2019 & 417 & 23,8 & 36,1 & 0,81 & 3,32 \\
\hline & Среднее & 419,2 & 18,8 & 37,5 & 0,70 & 2,90 \\
\hline \multirow{6}{*}{$A_{2}$} & 2015 & 441 & 27,0 & 40,7 & 1,10 & 4,81 \\
\hline & 2016 & 434 & 20,7 & 45,5 & 0,94 & 4,07 \\
\hline & 2017 & 435 & 29,2 & 41,5 & 1,21 & 5,28 \\
\hline & 2018 & 321 & 31,1 & 40,7 & 1,26 & 4,05 \\
\hline & 2019 & 479 & 34,9 & 33,3 & 1,16 & 5,54 \\
\hline & Среднее & 422,0 & 28,6 & 40,3 & 1,13 & 4,75 \\
\hline \multirow{6}{*}{$\mathrm{A}_{3}$} & 2015 & 479 & 27,1 & 38,0 & 1,03 & 4,92 \\
\hline & 2016 & 365 & 18,4 & 46,5 & 0,85 & 3,11 \\
\hline & 2017 & 498 & 29,8 & 41,9 & 1,25 & 6,21 \\
\hline & 2018 & 443 & 24,4 & 48,8 & 1,19 & 5,22 \\
\hline & 2019 & 511 & 28,5 & 37,8 & 1,06 & 5,45 \\
\hline & Среднее & 459,2 & 25,6 & 42,6 & 1,08 & 4,98 \\
\hline$P_{\mathrm{A} 1-\mathrm{A} 2}$ & & 0,156 & 0,014 & 0,085 & 0,043 & 0,032 \\
\hline$P_{A 2-A 3}$ & & 0,042 & 0,216 & 0,092 & 0,087 & 0,167 \\
\hline$P_{A 1-A 3}$ & & 0,029 & 0,021 & 0,040 & 0,048 & 0,029 \\
\hline
\end{tabular}


наблюдалась в 2016 г. ( $r=0,93)$ и в 2019 г. $(r=0,84)$, а массой 1000 зерен - в 2018 г $(r=0,95)$.

По местоположению в ландшафте корреляция урожайных данных озимой пшеницы после гороха на зерно показала сильную зависимость урожая зерна от веса зерна с колоса на таксоне $\mathrm{A}_{1}(r=0,85)$ и средней силы связь на таксоне $A_{3}(r=0,60)$. На таксоне $A_{2}$ выявить связь урожайности с элементами структуры не удалось.

По полупару влияние условий минерального питания достоверным было по продуктивному стеблестою в 2016-2018 гг., по массе 1000 зерен в 2015, 2016 и 2019 гг., по количеству зерен в колосе в 2019 г. и по урожайности по всем годам, кроме 2019 г. (табл. 2).

По колосовому предшественнику урожай зерна озимой пшеницы в 2015 г. формировался за счет продуктивного стеблестоя $(r=0,78)$ и массы зерна с колоса $(r=0,71)$, а в остальные годы (2016-2019) - по колосовому типу за счет массы зерна с колоса $(r=0,76-0,96)$. На таксоне $\mathrm{A}_{1}$ он формировался в основном за счет веса зерна с колоса $(r=0,83)$, а на таксоне $\mathrm{A}_{2}$ и $\mathrm{A}_{3}-$ за счет продуктивного стеблестоя к уборке (соответственно $r=0,84-0,85)$.

В среднем по предшественникам за 5 лет исследований наиболее сильная корреляционная связь урожай-

\section{ЛИТЕРАТУРА}

1. Кулинцев В.В., Годунова Е.И., Желнакова Л.И. и др. Система земледелия нового поколения Ставропольского края. Ставрополь: Агрус. 2013: 520

2. В. И. Елисеев, Г. Н. Сандакова. Влияние погодных факторов и различных доз минеральных удобрений на формирование элементов структуры урожая яровой мягкой пшеницы в Оренбургском Предуралье. Известия Оренбургского ГАУ. 2019;2(76):37-39.

3. Коваленко С.А., Грабовец А.И., Кадушкина В.П. Корреляционные взаимосвязи между урожаем и элементами его структуры у сортов яровой твердой пшеницы донской селекции. Известия Оренбургского государственного аграрного университета. 2017;5(67):31-33.

4. Петров Г.И. Влияние агрометеорологических условий на формирование урожая озимой пшеницы в сухостепной полосе Ставрополья. Издательство «Прикумье», 1996: 342.

5. Соколенко Н.И., Комаров Н.М. Оценка исходного материала озимой пшеницы по элементам структуры урожайности. Известия Горского ГАУ. 2019;56(4):26-31.

6. Ковтун В.И., Ковтун Л.Н., Сухарева А.А. Урожайность и элементы ее структуры у новых генотипов пшеницы мягкой озимой Северо-Кавказского ФНАЦ. Известия Оренбургского ГАУ. 2019;2(76):55-58.

7. Доспехов В.А. Методика полевого опыта (с основами статистической обработки результатов исследований). 2012: 352.

\section{ОБ АВTOPAX:}

Александр Иванович Хрипунов, кандидат сельскохозяйственных наук, ведущий научный сотрудник, заведующий лабораторией агроландшафтов, sniish@mail.ru

Елена Николаевна Общия, старший научный сотрудник лаборатории агроландшафтов, obzia@mail.ru

Наталья Алексеевна Галушко, кандидат биологических наук, ведущий научный сотрудник лаборатории качества зерна, sniish@mail.ru ности отмечалась с весом зерна с 1 колоса $(r=0,88)$, который тесно связан с массой 1000 зерен $(r=0,83)$ и количеством зерен в колосе $(r=0,82)$. На удобренном фоне выявлено достоверное различие по годам исследований по продуктивному стеблестою между таксонами $\mathrm{A}_{1}-\mathrm{A}_{3}$ и $\mathrm{A}_{2}-\mathrm{A}_{3}$, по количеству зерен в колосе, весу зерна с 1 колоса и урожаем между таксонами $A_{1}-A_{2}$ и $A_{1}-A_{3}$, а по массе 1000 зерен между $A_{1}$ и $A_{3}$ (табл. 3).

\section{Выводы}

Таким образом, по предшественнику горох в среднем по таксонам за все годы исследований достоверная разница между фонами питания была по всем элементам структуры урожая, кроме веса зерна с колоса, тогда как по полупару такая разница наблюдалась только по количеству продуктивных стеблей к уборке. Урожайность озимой пшеницы по фонам питания по обоим предшественникам статистически существенно различалась по всем годам, кроме 2019 года. В среднем по предшественникам достоверная разница по таксонам ландшафта отмечена между $\mathrm{A}_{1}$ и $\mathrm{A}_{2}$ по количеству зерен и весу зерна с колоса, между $\mathrm{A}_{2}$ и $\mathrm{A}_{3}$ по продуктивному стеблестою, между $A_{1}$ и $A_{3}$ по всем элементам структуры урожая.

\section{REFERENCES}

1. Kulintsev V.V., Godunova E.I., Zhelnakova L.I. and others. The new generation farming system of the Stavropol Territory. Stavropol: Agrus. 2013: 520. (In Russ.)

2. V. I. Eliseev, G. N. Sandakova. Influence of weather factors and various doses of mineral fertilizers on the formation of elements of the structure of the spring soft wheat yield in the Orenburg Cis-Urals. News of the Orenburg State Agrarian University. 2019;2(76):37-39. (In Russ.)

3. Kovalenko S.A., Grabovets A.I., Kadushkina V.P. Correlation relationships between the yield and elements of its structure in the varieties of spring durum wheat of the Don selection. Bulletin of the Orenburg State Agrarian University. 2017:5(67):31-33. (In Russ.)

4. Petrov G.I. Influence of agrometeorological conditions on the formation of winter wheat yield in the dry steppe zone of the Stavropol region. Prikumye Publishing House, 1996: 342. (In Russ.)

5. Sokolenko N.I., Komarov N.M. Assessment of the initial material of winter wheat by the elements of the yield structure. News of the Gorsky GAU. 2019;56(4):26-31. (In Russ.)

6. Kovtun V.I., Kovtun L.N., Sukhareva A.A. Productivity and elements of its structure in new genotypes of soft winter wheat of the North Caucasus Federal Research Center. News of the Orenburg State Agrarian University. 2019;2(76):55-58. (In Russ.)

7. Dospekhov V.A. Field experiment technique (with the basics of statistical processing of research results). 2012: 352. (In Russ.)

\section{ABOUT THE AUTHORS:}

Alexander I. Khripunov, Candidate of Agricultural Sciences, Leading Researcher, Head of the Laboratory of Agricultural Landscapes, sniish@mail.ru

Elena N. Obshchiya, Senior Researcher, Laboratory of Agricultural Landscapes, obzia@mail.ru

Natalia A. Galushko, Candidate of biology sciences, leading researcher of the laboratory of grain quality, sniish@mail.ru 